\title{
Splitting, impulsivity, and intimate partnerships in young obese women seeking bariatric treatment
}

\author{
Jana Zmolikova ${ }^{1,2}$ \\ Dita Pichlerova ${ }^{3}$ \\ Petr Bob ${ }^{1,4}$ \\ Denisa Schückova ${ }^{5}$ \\ Jitka Herlesova ${ }^{3}$ \\ Petr Weiss ${ }^{6}$ \\ 'Department of Psychiatry, First \\ Faculty of Medicine, Center for \\ Neuropsychiatric Research of \\ Traumatic Stress, Charles University, \\ ${ }^{2}$ Department of Clinical Psychology, \\ $\mathrm{Na}$ Homolce Hospital, ${ }^{3} \mathrm{OB}$ Clinic, \\ Prague, ${ }^{4}$ Faculty of Medicine, Central \\ European Institute of Technology, \\ Masaryk University, Brno, ${ }^{5}$ Iscare \\ Clinical Centre, ${ }^{6}$ Institute of Sexology, \\ First Faculty of Medicine, Charles \\ University, Prague, Czech Republic
}

Correspondence: Petr Bob Department of Psychiatry, First Faculty of Medicine, Center for Neuropsychiatric Research of Traumatic Stress, Charles University, Ke Karlovu I I, 12000 Prague 2, Czech Republic Email petrbob@netscape.net
This article was published in the following Dove Press journal:

Neuropsychiatric Disease and Treatment

16 September 2016

Number of times this article has been viewed

Background: Splitting represents a defense mechanism that describes fragmentation of conscious experience that may occur in various psychopathological conditions. The purpose of this study was to examine the relationship of splitting with disturbed cognitive and affective functions related to impulsivity and intimate partnerships in a group of obese patients indicated for bariatric treatment and compare the results with other obese patients and patients with bulimia nervosa.

Methods: In this clinical study, we assessed 102 young women. The sample was divided into three subgroups: obese women $(\mathrm{N}=30)$, obese women indicated for bariatric treatment $(\mathrm{N}=48)$, and patients with bulimia nervosa $(\mathrm{N}=24)$. The patients were assessed using Splitting Index and Barratt Impulsivity Scale, and selected information about their intimate partnership was documented for all the participants.

Results: The main results of this study indicate significant differences in the relationship of splitting and impulsivity with difficulties in intimate partnerships. These differences discriminate obese patients indicated for bariatric treatment from other obese patients and patients with bulimia nervosa.

Conclusion: These findings may have significant implications for treatment of the obese patients indicated for bariatric treatment and their presurgery psychological evaluations.

Keywords: splitting, impulsivity, obesity, bulimia nervosa, bariatric treatment

\section{Introduction}

According to recent findings, disturbed intimate relationships, sexual dysfunctions, and other mental health problems have high prevalence in obese women and are particularly significant in patients seeking bariatric surgery. ${ }^{1-8}$ For example, the results of one study show that $\sim 60 \%$ of the patients seeking bariatric surgery report sexual dysfunctions and other difficulties in sexual satisfaction and intimate relationships. ${ }^{2}$ On the other hand, several studies indicate that bariatric treatment may significantly improve these dysfunctions, quality of life, and decrease depressive symptoms. ${ }^{9-14}$

Recent studies indicate that obese women have higher impulsivity, ${ }^{15-18}$ and this impulsive behavior mainly increases in binge eating patients. ${ }^{19,20}$ On the other hand, some data show decreased nonfood-related impulsivity in patients who achieved a substantial weight loss after bariatric surgery. ${ }^{21}$

According to the current findings, there is no evidence how increased impulsivity and disturbed intimate partnerships are related to conflicting and unstable perceptual and emotional patterns represented by unexpected shifts between idealization and devaluation of other persons and the self, and this condition is described in the objective $\mathrm{BY}$
hereby accept the Terms. Non-commercial uses of the work are permitted without any further permission from Dove Medical Press Limited, provided the work is properly attributed. For permission for commercial use of this work, please see paragraphs 4.2 and 5 of our Terms (https://www.dovepress.com/terms.php).
forition 
relations theory as "splitting". ${ }^{22,23}$ Splitting reflects shifts of mind related to a consciously experienced conflict of opposing mental forces and fragmentation of conscious experience typically related to long-term or acute stressful experiences disturbing self-concept, identity, memory, and perception of the external world. ${ }^{22-26}$ Basic concept of splitting within object relations theory was described by Kernberg, ${ }^{22}$ who used the process of splitting as a specific characteristic of cognitive and affective disturbances in borderline personality disorder and other mental diseases with close links to impulsivity. ${ }^{22,27}$

As described earlier, in the current literature, there is no evidence about specific relationships of splitting and impulsivity with other mental health problems in patients with eating disorders, although increased impulsivity has been reported in these patients. ${ }^{15-18}$ In this context, the purpose of this study was to examine the relationships of psychological process of splitting and impulsivity with problems in intimate relationships in patients manifesting recurrent overeating, specifically focusing on patients seeking bariatric treatment.

\section{Methods}

\section{Participants}

In this cross-sectional study, the participants were recruited from outpatients of the $\mathrm{Na}$ Homolce Hospital in Prague. All participants signed informed consent and the study was approved by Charles University ethical committee. The participants had been diagnosed with obesity or mental bulimia characterized by recurrent overeating, and these data samples were collected according to power analysis of the previous results with respect to most probable statistical significance in subsamples defined by diagnostic criteria. Exclusion criteria were organic illnesses involving the central nervous system, substance and/or alcohol abuse, and mental retardation (IQ [Raven] lower than 90). ${ }^{28}$ Clinical diagnoses were based on The Diagnostic and Statistical Manual of Mental Disorders-IV (DSM-IV) criteria, and all clinical assessments were done using clinical interviews. In the clinical study, we assessed 102 young women (mean age 26.42 years; standard deviation $[\mathrm{SD}]=4.016$; age range $18-37$ years) predominantly with high school education. The sample was divided into three subgroups: obese women $(\mathrm{N}=30)$, obese women indicated for bariatric treatment $(\mathrm{N}=48)$, and patients with bulimia nervosa $(\mathrm{N}=24)$. The patients were assessed using Splitting Index (SI) and Barratt Impulsivity Scale (BIS), and selected information regarding their intimate partnership was documented for all the participants. This assessment of intimate relationships mainly focused on the number of intimate relationships lasting longer than 6 months, age at the first coitus, number of sexual partners during lifetime, number of occasional sexual partners during lifetime, sexual intercourse out of partnership, and satisfaction with sexual life.

\section{Psychometric measures}

The symptoms of splitting were measured using self-reported Splitting Index $(\mathrm{SI})^{23}$ that has been proposed to test the defense mechanisms described by Kernberg. ${ }^{22}$ SI is a 24-item self-reported questionnaire assessed on a five-point Likert scale from 1 to 5 (Cronbach's alpha 0.92).

Symptoms of impulsivity were measured using selfreported eleventh revised version of the Barratt Impulsivity Scale (BIS-11). ${ }^{29}$ The BIS-11 is a 30-item self-reported questionnaire assessed on a four-point Likert Scale from 1 to 4 (Cronbach's alpha 0.82).

\section{Statistical methods}

Statistical evaluations of psychometric measures included mean, standard deviation, Spearman correlation, and Kruskal-Wallis analysis of variance (ANOVA). All the methods of statistical evaluation were performed using the software package Statistica version 6 .

\section{Results}

The group of participants $(\mathrm{N}=102)$ was divided into three subgroups. These subgroups included obese women $(\mathrm{N}=30)$, obese women indicated for bariatric treatment $(\mathrm{N}=48)$, and patients with bulimia nervosa $(\mathrm{N}=24)$. Analysis of the data using Kruskal-Wallis ANOVA statistically significantly discriminates all the assessed parameters (number of sexual partners during lifetime, number of occasional sexual partners during lifetime, sexual intercourse out of partnership, and satisfaction with sexual life) between the subgroups of obese patients indicated for bariatric treatment and the other obese patients (with exception of age at the first coitus; $\mathrm{z}>3.077, P<0.0063)$. The results of the Kruskal-Wallis ANOVA do not distinguish certain variables discriminating between bariatric patients and bulimia nervosa (eg, number of sexual partners during lifetime, number of occasional sexual partners during lifetime; Table 1). The results show significantly higher level of splitting and impulsivity among bariatric patients in comparison to the other obese patients but lower levels of impulsivity and splitting in bariatric patients compared to the patients with bulimia nervosa.

Other results of this study show specific relationships of splitting and impulsivity with variables indicating intimate 
Table I Statistical comparison of obese patients indicated for bariatric treatment with the control groups of other obese patients and patients with bulimia nervosa

\begin{tabular}{|c|c|c|c|}
\hline Variables & $\begin{array}{l}\text { Obese } \\
\text { (bariatric) }\end{array}$ & Obese & $\begin{array}{l}\text { Bulimia } \\
\text { nervosa }\end{array}$ \\
\hline \multicolumn{4}{|l|}{ Age, years } \\
\hline Mean & 26.39 & 26.82 & 26.68 \\
\hline SD & 0.64 & 0.84 & 0.90 \\
\hline $\begin{array}{l}\text { Marital status, mean (single =I, } \\
\text { married }=2 \text { ) }\end{array}$ & 1.50 & 1.18 & 1.16 \\
\hline \multicolumn{4}{|l|}{ Weight } \\
\hline Mean & 119.08 & 94.50 & 59.21 \\
\hline SD & 2.64 & 3.47 & 3.73 \\
\hline \multicolumn{4}{|l|}{$\mathrm{BMI}, \mathrm{kg} / \mathrm{m}^{2}$} \\
\hline Mean & 41.90 & 31.97 & 21.42 \\
\hline SD & 0.83 & 1.09 & 1.17 \\
\hline Age at the first coitus & $16.6 \mathrm{I}$ & 17.41 & 16.84 \\
\hline $\begin{array}{l}\text { Number of intimate relationships } \\
\text { longer than } 6 \text { months }\end{array}$ & 2.13 & 2.27 & 2.37 \\
\hline $\begin{array}{l}\text { Number of sexual partners during } \\
\text { lifetime }\end{array}$ & 10.95 & 7.27 & 12.95 \\
\hline $\begin{array}{l}\text { Number of occasional sexual } \\
\text { partners during lifetime }\end{array}$ & 4.24 & 1.59 & 6.05 \\
\hline $\begin{array}{l}\text { Sexual intercourse out of } \\
\text { partnership }(\mathrm{No}=1, \text { Yes }=2)\end{array}$ & 1.42 & 1.50 & 1.47 \\
\hline $\begin{array}{l}\text { Satisfaction with sexual life }(\mathrm{No}=\mathrm{I} \text {, } \\
\text { Yes }=2)\end{array}$ & 1.62 & 1.56 & 1.43 \\
\hline \multicolumn{4}{|l|}{ BIS } \\
\hline Mean & 46.95 & 40.50 & 55.13 \\
\hline SD & 4.45 & 5.85 & 6.30 \\
\hline $\mathrm{Cl}-95 \%$ & 38.10 & 28.86 & 42.6 \\
\hline $\mathrm{Cl}+95 \%$ & 55.81 & 52.15 & 67.67 \\
\hline \multicolumn{4}{|l|}{ SI } \\
\hline Mean & 88.65 & 75.59 & 104.95 \\
\hline$S D$ & 8.89 & 11.68 & 12.57 \\
\hline $\mathrm{Cl}-95 \%$ & 70.95 & 52.34 & 79.92 \\
\hline $\mathrm{Cl}+95 \%$ & 106.34 & 98.85 & 129.77 \\
\hline
\end{tabular}

Abbreviations: SD, standard deviation; BMI, body mass index; BIS, Barratt Impulsivity Scale; $\mathrm{Sl}$, Splitting Index; $\mathrm{Cl}$, confidence interval. partnerships in the patients looking for bariatric treatment and their comparison with the control group of obese patients and patients with bulimia nervosa (Table 2).

The results also show significant positive correlations of splitting and impulsivity with higher number of sexual partners during lifetime, number of occasional sexual partners during lifetime, and sexual intercourse out of partnership, and negative correlations of high level of splitting and impulsivity with lower satisfaction with sexual life and younger age at the first coitus (Table 2).

In summary, the results distinguish bariatric subgroup of patients from the other patients in their subjective experiences of sexual life. These experiences in bariatric patients manifest significant relationships with splitting and impulsivity that were not observed in the other obese patients and the control subgroup of patients with bulimia nervosa (Table 2).

\section{Discussion}

The main results of this study indicate significant differences in splitting, impulsivity, and difficulties in intimate relationships that discriminate obese patients indicated for bariatric treatment from the other obese patients and patients with bulimia nervosa. These data show higher levels of splitting and impulsivity among bariatric patients in comparison to the other obese patients. On the other hand, bariatric patients have lower levels of impulsivity and splitting in comparison to the patients with bulimia nervosa, who in agreement with recent findings have significant difficulties with impulsive behavior and other mental health problems. ${ }^{30,31}$ The results also show specific differences in patients indicated to bariatric treatment, suggesting a close relationship of satisfaction in intimate relationships with symptoms of impulsivity and

Table 2 Associations of splitting and impulsivity with variables describing intimate relationships

\begin{tabular}{|c|c|c|c|c|c|c|c|c|}
\hline \multirow[t]{2}{*}{ Variables } & \multicolumn{2}{|c|}{ Whole sample } & \multicolumn{2}{|l|}{ Obese } & \multicolumn{2}{|c|}{ Obese bariatric } & \multicolumn{2}{|c|}{ Bulimia nervosa } \\
\hline & BIS & SI & BIS & SI & BIS & SI & BIS & SI \\
\hline Age & 0.01 & 0.00 & -0.03 & -0.05 & 0.12 & 0.12 & -0.10 & -0.10 \\
\hline Marital status & $-0.38 * *$ & $-0.38^{* *}$ & $-0.42 *$ & $-0.42^{*}$ & $-0.39 * *$ & $-0.39 * *$ & -0.02 & -0.02 \\
\hline Education & -0.08 & -0.08 & -0.29 & -0.30 & -0.15 & -0.15 & 0.07 & 0.06 \\
\hline Weight & $-0.28 * *$ & $-0.29 * *$ & -0.21 & -0.22 & -0.08 & -0.08 & 0.19 & 0.19 \\
\hline Body mass index & $-0.27^{* *}$ & $-0.27^{* *}$ & -0.08 & -0.09 & -0.11 & -0.10 & 0.24 & 0.24 \\
\hline Age at the first coitus & $-0.42 * *$ & $-0.42 * *$ & $-0.49 * *$ & $-0.49 * *$ & $-0.4 I^{* *}$ & $-0.40 * *$ & $-0.48^{*}$ & $-0.48^{*}$ \\
\hline No of intimate relationships longer than 6 months & $0.45^{* *}$ & $0.44^{* *}$ & $0.75 * *$ & $0.75 * *$ & $0.4 I^{* *}$ & $0.4 I^{* *}$ & 0.18 & 0.18 \\
\hline No of sexual partners during lifetime & $0.89 * *$ & $0.89 * *$ & $0.91 * *$ & $0.91 * *$ & $0.88 * *$ & $0.89 * *$ & $0.80 * *$ & $0.8 I * *$ \\
\hline No of occasional sexual partners during lifetime & $0.80 * *$ & $0.80 * *$ & $0.68 * *$ & $0.68 * *$ & $0.83 * *$ & $0.83 * *$ & $0.78 * *$ & $0.79 * *$ \\
\hline Sexual intercourse out of partnership & $0.50 * *$ & $0.49 * *$ & $0.48 * *$ & $0.48 * *$ & $0.57^{* *}$ & $0.56 * *$ & $0.43^{*}$ & $0.43^{*}$ \\
\hline Satisfaction with sexual life & $-0.28 * *$ & $-0.29 * *$ & -0.01 & 0.00 & $-0.4 I^{* *}$ & $-0.4 \mid * *$ & -0.08 & -0.07 \\
\hline BIS & - & $0.99 * *$ & - & $0.99 * *$ & - & $0.99 * *$ & - & $0.99 * *$ \\
\hline
\end{tabular}

Notes: $* P<0.05 ; * * P<0.01$

Abbreviations: BIS, Barratt Impulsivity Scale; SI, Splitting Index. 
splitting, which distinguishes bariatric patients from other obese patients and patients with bulimia nervosa. One of the most important findings of this study with respect to future research is the close relationship of satisfaction in intimate relationships with symptoms of impulsivity and splitting that would be very useful to assess in longitudinal studies. These data are in agreement with findings indicating that women seeking bariatric surgery represent a population with $\sim 60 \%$ occurrence of substantial sexual function impairment ${ }^{2}$ that is significantly related to disturbed partnerships. ${ }^{11-14}$

\section{Conclusion}

The novel finding of this study represents the relationship between cognitive and affective disturbances in bariatric patients and the process of splitting. These results show that the scores of splitting in bariatric patients are significantly higher in comparison to the other obese patients but lower than in patients with bulimia nervosa. These findings may have significant implications for treatment of the obese patients indicated for bariatric treatment and possible influences of psychotherapy. In addition, these data suggest that a detailed examination of unstable patterns of identity and intimate relationships may have significant implications for conceptualization and understanding of psychological factors in the pathogenesis of obesity per se. In this context, future studies could consider other important factors and data which are not included in this study and represent certain limitations with respect to more detailed knowledge about the process of splitting in these patients. For example, relationships of the symptoms of splitting with specific symptoms that manifest in patients with eating disorders and other psychopathological symptoms, such as symptoms of traumatic stress, depression, anxiety, and dissociative symptoms, might be useful to consider, and more detailed assessment and analysis of the symptoms associated with borderline personality disorder and more details about the intimate partnerships would be useful to investigate. This suggests a hypothesis for further research that the higher levels of splitting may be related to increased occurrence of noncompliance and nonadherence to postsurgery adaptation and presurgery psychological evaluation to indicate or contraindicate the bariatric treatment.

\section{Acknowledgments}

The study was supported by the Charles University grant (PRVOUK and SVV), Project GACR P407/12/1957, and the project "CEITEC - Central European Institute of Technology" (CZ.1.05/1.1.00/02.0068) from the European Regional Development Fund.

\section{Disclosure}

The authors report no conflicts of interest in this work.

\section{References}

1. Kolotkin RL, Binks M, Crosby RD, Ostbye T, Gress RE, Adams TD. Obesity and sexual quality of life. Obesity (Silver Spring). 2006;14(3): 472-479.

2. Bond DS, Vithiananthan S, Leahey TM, et al. Prevalence and degree of sexual dysfunction in a sample of women seeking bariatric surgery. Surg Obes Relat Dis. 2009;5(6):698-704.

3. Bond DS, Wing RR, Vithiananthan S, et al. Significant resolution of female sexual dysfunction after bariatric surgery. Surg Obes Relat Dis. 2011;7(1):1-7.

4. Danes L, Raboch J, Sonka J. Sexual development and life of obese women. Cesk Gynekol. 1990;55(3):173-178.

5. Danes L, Sonka J, Raboch J. Sexual development in obese women. Cesk Psychiatr. 1990;86(6):375-378.

6. Glinski J, Wetzler S, Goodman E. The psychology of gastric bypass surgery. Obes Surg. 2001;11(5):581-588.

7. Esposito K, Ciotola M, Giugliano F, et al. Association of body weight with sexual function in women. Int J Impot Res. 2007;19(4):353-357.

8. KaneshiroB, JensenJT, CarlsonNE, Harvey SM, Nichols MD, Edelman AB. Body mass index and sexual behavior. Obstet Gynecol. 2008;112(3): 586-592.

9. Rand CS, Kuldau JM, Robbins L. Surgery for obesity and marriage quality. JAMA. 1982;247(10):1419-1422.

10. Camps MA, Zervos E, Goode S, Rosemurgy AS. Impact of bariatric surgery on body image perception and sexuality in morbidly obese patients and their partners. Obes Surg. 1996;6(4):356-360.

11. Assimakopoulos K, Panayiotopoulos S, Iconomou G, et al. Assessing sexual function in obese women preparing for bariatric surgery. Obes Surg. 2006;16(8):1087-1091.

12. Assimakopoulos K, Karaivazoglou K, Panayiotopoulos S, Hyphantis T, Iconomou G, Kalfarentzos F. Bariatric surgery is associated with reduced depressive symptoms and better sexual function in obese female patients: a one-year follow-up study. Obes Surg. 2011;21(3): 362-366.

13. Kinzl JF, Trefalt E, Fiala M, Hotter A, Biebl W, Aigner F. Partnership, sexuality, and sexual disorders in morbidly obese women: consequences of weight loss after gastric banding. Obes Surg. 2001;11(4): 455-458.

14. Wadden TA, Sarwer DB, Fabricatore AN, Jones L, Stack R, Williams NS. Psychosocial and behavioral status of patients undergoing bariatric surgery: what to expect before and after surgery. Med Clin North Am. 2007; 91(3):451-469.

15. Mobbs O, Van Der Linden M, Golay A. Impulsivity - is one of the factors responsible for obesity. Rev Med Suisse. 2007;3(105):850-853.

16. Hofmann J, Ardelt-Gattinger E, Paulmichl K, et al. Dietary restraint and impulsivity modulate neural responses to food in adolescents with obesity and healthy adolescents. Obesity (Silver Spring). 2015;23(11): 2183-2189.

17. Bongers $\mathrm{P}$, van de Giessen $\mathrm{E}$, Roefs A, et al. Being impulsive and obese increases susceptibility to speeded detection of high-calorie foods. Health Psychol. 2015;34(6):677-685.

18. Lawyer SR, Boomhower SR, Rasmussen EB. Differential associations between obesity and behavioral measures of impulsivity. Appetite. 2015; 95:375-382.

19. Crépin C, Carrard I, Perroud A, Van der Linden M, Golay A. Managing impulsivity in obesity with problem solving. Rev Med Suisse. 2010; 6(231):46-50.

20. Schag K, Schönleber J, Teufel M, Zipfel S, Giel KE. Food-related impulsivity in obesity and binge eating disorder - a systematic review. Obes Rev. 2013;14(6):477-495.

21. Georgiadou E, Gruner-Labitzke K, Köhler H, de Zwaan M, Müller A. Cognitive function and nonfood-related impulsivity in post-bariatric surgery patients. Front Psychol. 2014;5:1502. 
22. Kernberg OF. Borderline Conditions and Pathological Narcissism. New York: Janson Aronson; 1975.

23. Gould JR, Prentice NM, Ainslie RC. The Splitting Index: construction of a scale measuring the defense mechanism of splitting. J Pers Assess. 1996;66(2):414-430.

24. Kohut H. The Analysis of the Self. New York: International Universities Press; 1971.

25. Stone MH. Toward a psychobiological theory of borderline personality disorder: is irritability the red thread that runs through borderline conditions? Dissociation. 1988;1:2-15.

26. Bob P. Pain, dissociation and subliminal self-representations. Conscious Cogn. 2008;17:355-369.

27. Gunderson JG, Lyons-Ruth K. BPD's interpersonal hypersensitivity phenotype: a gene-environment-developmental model. J Pers Disord. 2008;22(1):22-41.
28. Raven JC. Guide to the Standard Progressive Matrices. London: HK Lewis; 1960.

29. Patton JH, Stanford MS, Barratt ES. Factor structure of the Barratt impulsiveness scale. J Clin Psychol. 1995;51(6):768-774.

30. Lavender JM, Wonderlich SA, Engel SG, Gordon KH, Kaye WH, Mitchell JE. Dimensions of emotion dysregulation in anorexia nervosa and bulimia nervosa: a conceptual review of the empirical literature. Clin Psychol Rev. 2015;40:111-122.

31. Pearson CM, Wonderlich SA, Smith GT. A risk and maintenance model for bulimia nervosa: from impulsive action to compulsive behavior. Psychol Rev. 2015;122(3):516-535.
Neuropsychiatric Disease and Treatment

\section{Publish your work in this journal}

Neuropsychiatric Disease and Treatment is an international, peerreviewed journal of clinical therapeutics and pharmacology focusing on concise rapid reporting of clinical or pre-clinical studies on a range of neuropsychiatric and neurological disorders. This journal is indexed on PubMed Central, the 'PsycINFO' database and CAS,

\section{Dovepress}

and is the official journal of The International Neuropsychiatric Association (INA). The manuscript management system is completely online and includes a very quick and fair peer-review system, which is all easy to use. Visit http://www.dovepress.com/testimonials.php to read real quotes from published authors.

Submit your manuscript here: http://www.dovepress.com/neuropsychiatric-disease-and-treatment-journal 